Rural women's empowerment in nutrition: a proposal for diagnostics linking food, health and institutions

Sudha Narayanan, Marzia Fontana, Erin Lentz, and Bharati Kulkarni

Indira Gandhi Institute of Development Research, Mumbai February 2019 


\title{
Rural women's empowerment in nutrition: a proposal for diagnostics linking food, health and institutions
}

\author{
Sudha Narayanan, Marzia Fontana, Erin Lentz, and Bharati Kulkarni
}

Email(corresponding author): sudha@igidr.ac.in

\begin{abstract}
This paper explores the concept of women's nutritional empowerment and develops a framework for operationalizing it. The paper specifically focuses on the nutritional outcomes of women themselves, rather than on their children. The emphasis on nutritional empowerment addresses an important gap in both literature and policy practice relating to gender equality, agriculture and food security. Interventions to enhance agricultural productivity and food production do not always translate into improved nutritional outcomes. Further, agricultural interventions claiming to promote the economic empowerment of women but focusing exclusively on income-generating opportunities may inadvertently increase their work burden (both paid and unpaid) and undermine their health and nutrition. The proposed framework includes the domains of food, health, and institutions and articulates their multiple linkages. Both paid and unpaid work are important mediating factors in these interactions. We aim to identify specific individual constraints as well as broader structural factors that may prevent rural women from achieving adequate nutritional outcomes and to develop tools to assess the relative weight of these factors in different contexts. The analysis draws on quantitative and qualitative data from Bangladesh and India but, with further validation, could have wider applicability. We hope this exercise could provide the basis for a first-cut of a gender and nutrition diagnostic tool to support efforts to promote well-targeted policies for nutritional security, specifically of rural women.
\end{abstract}

Keywords: Nutritional empowerment, women, rural, agency, resource, achievements

JEL Code: J16, D13, I00, I3 


\title{
Rural women's empowerment in nutrition: a proposal for diagnostics linking food, health and institutions ${ }^{1}$
}

\author{
Sudha Narayanan, Marzia Fontana, Erin Lentz, and Bharati Kulkarni ${ }^{2}$
}

\footnotetext{
${ }^{1}$ This paper was written as a contribution to the Expert Group Meeting on the priority theme of the $66^{\text {th }}$ Session of the Commission on the Status of Women (CSW 66) "Challenges and opportunities in achieving gender equality and the empowerment of rural women and girls" organized by UN Women in collaboration with the FAO, IFAD and WFP in Rome, on 20-22 September 2017. It draws on an ongoing project aimed at constructing a Women in Nutrition Empowerment Index (WENI) supported by Competitive Research Grants to Develop Innovative Methods and Metrics for Agriculture and Nutrition Actions (IMMANA Grants), an initiative funded with UK aid from the British people, and a Policy Research Institute grant from the LBJ School, UT Austin. We thank Sweta Bhushan, Ghida Ismail, Mohit Sharma, Udayan Rathore, and Tiffany Wang for assistance and Ruth Meinzen-Dick, Anuradha De and participants at the EGM for valuable discussions and comments.

${ }^{2}$ Sudha Narayanan is Associate Professor, Indira Gandhi Institute of Development Research (IGIDR), Mumbai, India; Marzia Fontana is an independent researcher based in Brighton, UK; Erin Lentz is Assistant Professor at the Lyndon B Johnson School of Public Affairs, University of Texas, Austin, USA; Bharati Kulkarni is Senior Grade Deputy Director at the National Institute of Nutrition, Hyderabad, India.
} 


\title{
Rural women's empowerment in nutrition:
}

\section{a proposal for diagnostics linking food, health and institutions}

\author{
Sudha Narayanan, Marzia Fontana, Erin Lentz, and Bharati Kulkarni
}

\begin{abstract}
This paper explores the concept of women's nutritional empowerment and develops a framework for operationalizing it. The paper specifically focuses on the nutritional outcomes of women themselves, rather than on their children. The emphasis on nutritional empowerment addresses an important gap in both literature and policy practice relating to gender equality, agriculture and food security. Interventions to enhance agricultural productivity and food production do not always translate into improved nutritional outcomes. Further, agricultural interventions claiming to promote the economic empowerment of women but focusing exclusively on incomegenerating opportunities may inadvertently increase their work burden (both paid and unpaid) and undermine their health and nutrition. The proposed framework includes the domains of food, health, and institutions and articulates their multiple linkages. Both paid and unpaid work are important mediating factors in these interactions. We aim to identify specific individual constraints as well as broader structural factors that may prevent rural women from achieving adequate nutritional outcomes and to develop tools to assess the relative weight of these factors in different contexts. The analysis draws on quantitative and qualitative data from Bangladesh and India but, with further validation, could have wider applicability. We hope this exercise could provide the basis for a first-cut of a gender and nutrition diagnostic tool to support efforts to promote well-targeted policies for nutritional security, specifically of rural women.
\end{abstract}

\section{Introduction}

Poor rural women's lives are characterized - more so than rural men's by a multiplicity of tasks and responsibilities. This is a reflection and consequence of women's work including both productive and reproductive (care) activities while men's work tends to focus primarily on production (FAO-IFAD-ILO 2010). As noted in a recent UN World Survey on the Role of Women in Development (UN Women 2014), governments and donors increasingly target women as important agents for promoting sustainable food production and protecting the environment. But if projects are designed without due consideration to the interdependencies and conflicts between women's productive and reproductive roles, the norms that govern these roles and the 
consequences for women's overall work burden, gender inequalities may intensify. Further, even projects leading to empowering experiences in one area of a woman's life (e.g. a greater say in agricultural production decisions) do not automatically translate into her greater capacity to make choices and transform power relations in another area of her life (e.g. entitlement to an adequate and nutritious diet). Thus, if improving nutrition is a goal of agricultural interventions, it is crucial to understand how to identify and address the constraints women face in multiple domains.

To this end, we propose a set of tools and metrics that provide the basis for an index, the Women's Empowerment in Nutrition Index (WENI), which would measure nutritional empowerment and include a number of factors relevant to achieving better nutritional outcomes for women. The index is still 'under construction'. In this particular paper, we focus on describing the constitutive elements of our main heuristic device, the WENI grid, which organizes factors contributing to nutritional empowerment by various dimensions and domains. We also show how the WENI grid can be used as the starting point for some basic diagnostic exercise (and not just for the construction of a full- blown index). We hope such tools may become regularly used to inform policies for achieving nutritional security of rural women, thus contributing to the gender-responsive implementation of Sustainable Development Goal 2 (SDG2).

Our effort directly responds to a gap in current work on gender, agriculture and nutrition but could have wider relevance even outside of agriculture. We identify two major concerns regarding research and policy practice on gender, agriculture and nutrition.

First, existing food-systems literature considers multiple pathways from agriculture to nutrition and indeed includes gender as an important component (Hawkes et al. 2012; Hoddinott et al. 2012 Gomez et al. 2013; Kadiyala et al. 2014; Pinstrup-Andersen 2014). However, current approaches either incorporate it as a theoretical driver, often represented in a figure but empirically unexplored (Pinstrup-Andersen 2014), or reduce its complexity to a single factor, such as time allocation (Gomez et al. 2013). Such framings of gender eschew a multi-dimensional approach (Kabeer 1999; Robeyns 2003; 
Alkire et al. 2012) and tend to neglect the variety of factors affecting women's knowledge and capacity to secure nutrition for themselves.

The second concern relates to the mixed evidence on the impact of agricultural interventions on gender differentiated nutritional outcomes. Linkages between agricultural production, care practices and nutrition are mediated strongly through gender norms both in agricultural work and care provision (Meinzen-Dick et al. 2012). Yet, evidence of improved nutritional outcomes resulting from interventions in agriculture is, thus far, limited, especially regarding gender-based linkages (Dangour et al. 2012; Hawkes et al. 2012; Haddad 2013; Kadiyala et al. 2014; Pinstrup-Andersen 2014). Some studies have found positive relationships between improvements in agricultural practices (e.g., irrigation) and nutritional outcomes of children and or their mothers (Bhagowalia et al. 2012). A few studies have found that women's engagement in agriculture may be associated with adverse child health outcomes or undermine their own health status and well-being (see Kadiyala et al. 2014 for a review). Other studies point toward positive impacts on intermediary outcomes for the household as a whole (such as dietary diversity and household production and consumption), but not on actual nutritional outcomes for individual household members (e.g. Leroy et al. 2009). Differences in the extent to which women are empowered in the sphere of nutrition may contribute to the mixed findings.

Among existing measures of women's empowerment, the Women's Empowerment in Agriculture Index (WEAI) is innovative in its focus on decisionmaking in the productive sphere and control over economic resources within the agricultural sector (Alkire et al. 2012). ${ }^{3}$ More specifically, WEAI measures the nature and extent of women's involvement in the agriculture sector in five domains: (1) decisions about agricultural production, (2) access to and decisionmaking power over productive resources, (3) control over use of income, (4) leadership in the community, and (5) time use. It also incorporates a comparative perspective of women's empowerment relative to men within their households. WEAI was originally developed to track changes in women's empowerment as a direct or indirect result of a US government initiative to fight

\footnotetext{
${ }^{3}$ http://www.ifpri.org/publication/womens-empowerment-agriculture-index
} 
global hunger and to improve food security (Feed the Future), and is increasingly used by a range of development organizations to inform efforts to promote rural women's economic empowerment. ${ }^{4}$

Recent analyses attempting to establish the relationship between WEAI scores and nutrition-related variables (such as per capita calorie availability, dietary diversity and adult BMI) find mixed evidence that being empowered in the agricultural domain is correlated with improved nutritional status (Malapit and Quisumbing 2014 for Ghana; Sraboni et al. 2014 for Bangladesh; Malapit et al. 2015 for Nepal). Such findings highlight the need for a complementary set of measures and indicators that more explicitly captures the pathways leading to women's empowerment in nutrition. The goal of this paper is to conceptualize nutritional empowerment and present a related diagnostic tool.

The paper is organized as follows. Section II defines nutritional empowerment and its interrelated dimensions. Section III identifies the WENI grid domains that are especially relevant to achieve nutritional outcomes, with focus on food, health and the norms and institutions regulating access to relevant resources. For each broad domain, specific factors potentially contributing to empowerment are analysed and further categorized by dimension of empowerment, drawing on formative research from Bangladesh and India. In section IV, we develop a diagnostic tool to decompose each element of the WENI grid. We demonstrate the usefulness of this approach by applying it to the analysis of binding constraints to the achievement of women's empowerment and nutritional status in one Indian state, relative to other states. Finally, we conclude with some policy implications.

\section{Conceptualizing Nutritional Empowerment}

We define nutritional empowerment as the process by which individuals acquire the capacity to be well fed and healthy. This process entails gaining access to, and control over, intakes of food which is adequate and nutritious; having knowledge about, and a say over, nutritional and health practices; and being able to draw

\footnotetext{
${ }^{4}$ On current initiatives and WEAI adaptations see for instance ongoing ILO-IFAD initiative in the MENA region ('WEAI youth'http://www.ilo.org/employment/areas/youthemployment/WCMS_418988/lang--en/index.htm ).
} 
support from both family and other institutions in securing and maintaining an adequate diet and health. When we speak specifically of nutritional empowerment of women, the nutritional outcomes we focus on are those of women themselves, rather than of their children.

We acknowledge that women might be well-fed and healthy without their empowerment having led to it. This may be the case in contexts where food and other material resources are abundant and easily available. But we are especially concerned about situations of scarcity and deprivation. In these situations, a woman's knowledge and capacity to act to secure food might make a difference to her nutritional status, particularly in the face of strong discriminatory gender norms. It therefore matters if nutritional outcomes reflect a meaningful choice or not.

Our conceptualization draws on key contributions in the women's empowerment literature such as Kabeer (1999), Robeyns (2003), and Alkire et al. (2013). Kabeer defines empowerment as the '... expansion in people's ability to make strategic life choices in a context where this ability was previously denied to them (p.19)'. She argues that changes in the ability to exercise choice involve changes in three inter-related dimensions that make up choice: resources (the conditions under which the choices are made), agency (the ability to define one's goals and act upon them; both of which are central to the process by which choices are made), and achievements (the outcomes of choices). Kabeer argues that these dimensions are inter-dependent because changes in each contribute to, and benefit from, changes in the others. For instance, gaining greater access to resources enables individuals to use their agency in order to achieve the outcomes they desire. In turn, '... the achievements of a particular moment are translated into enhanced resources or agency, and hence capacity for making choices, at a later moment in time" (p. 20).

Kabeer includes under 'resources' not only conventional economic and material resources but also various human and social resources. Human resources, in her definition, are embodied in the individual and encompass her/his knowledge, skills and creativity. Social resources, on the other hand, 
relate to the claims and obligations that characterize the broad set of relationships individuals are involved in different spheres of life, and which enable them to improve their situation beyond what would be possible through their individual efforts alone. Kabeer (1999) points out that access to resources is determined by the rules and practices prevailing in different institutions (family, employment relations, public sector entitlements, etc.) and that, crucially, "the terms on which people gain access to resources are as important as the resources themselves when the issue of empowerment is being considered" (p.20). In other words, empowerment may result from a change in the terms on which resources are acquired as much as from an increase in the resource base.

With reference to agency, Kabeer points out that although this tends to be operationalized mostly as individual decision-making, in reality it involves a wider range of purposive actions including, among others, cognitive processes of both individual and collective reflection. Resources and agency together constitute what Amartya Sen (1999) refers to as 'capabilities'.

Achievements, the third dimension of Kabeer's dimensions of empowerment, refer to the particular ways of being and doing that individuals are able to realize.

\section{Dimensions of nutritional empowerment}

For the purpose of our analysis, we identify four dimensions of nutritional empowerment. We begin with Kabeer's: resources, agency, and achievements. We also single out knowledge, meaning having information, as a separate resource from economic and social resources. In our operationalization of resources, we consider material, and social resources as well as the terms and norms that define access to them. We understand agency as both individual and collective agency. We define achievements as well-being outcomes.

Knowledge

We consider knowledge to be an important resource that is distinct from material and social resources. Because we are interested in better tracing the barriers women face to making strategic life choices, we aim to disentangle lack of knowledge about material and social resource versus actual lack of such 
resources. In some ways, knowledge precedes the other three dimensions. Individuals need to have knowledge about the resources they have a right to before they can leverage them. This differentiation of knowledge from other resources has value from a policy perspective, as we can identify whether expanding knowledge about services alleviates a constraint for a particular population. Providing knowledge is often at the heart of interventions that aim to effect behavioural change. Providing knowledge is also a core component of rights based work in that citizens may not have adequate information about what institutional services are available and to whom. Knowledge, then, is a necessary but often not sufficient condition for empowerment, especially if women do not have then other resources to translate what they know into action.

\section{Material and Social Resources}

Our definition of material and social resources fully reflects Kabeer's. Resources are acquired through multiplicity of social relationships conducted in the various institutional domains, which make up a society (such as family, market, community). These include various kinds of rights over these resources ownership, fructus, and so forth. We too stress that the terms through which people gain access to economic and social resources (shaped by the various social relations they are part of) matter as much as the resources themselves. Also included in resources are the rules and practices prevailing in different institutions, such as women's abilities to access markets, which vary both across communities and within them.

\section{Agency and Autonomy}

Agency refers broadly to the ability to define one's goals and to act upon them. By agency we mean both executive and implementation decisions (Kabeer 1999). We distinguish between the ability to (jointly) make executive decisions within a household (e.g., to fix a budget) and the ability to implement a decision (e.g., buy food with a fixed budget). But we recognize there is an important difference between the two types of decisions. For example, being given a set budget for food and being told to purchase food for the family (an 
implementation decision) may not be 'empowering' at all. It may rather turn into a stressful exercise if the given budget is very limited and expectations around a woman's responsibility to feed the family are high. In other words, this is evidence of women making choices within a limited budget, but not of their ability to gain access to a greater share of that budget.

Another aspect of agency is autonomy or authentic self-direction that has its roots in Self Determination theory (SDT). Autonomy refers to actions that the person values and has reason to value. Recognizing that motivations are complex, SDT distinguishes the extent to which actions are undertaken because of their value or due to social pressure or active coercion (Vaz et al. 2016). People are most autonomous when they act in accord with their authentic interests or integrated values and desires. ${ }^{5}$ Synergy between autonomy, knowledge and resources is essential for positive outcomes.

\section{Achievements}

Achievements are the starting point of enquiry for the diagnostic tool and allow us to identify binding constraints. Similar to Kabeer, we consider achievements, or well-being outcomes, as demonstrating that people are able to actualize their agency. For this reason, a diagnostic tool focusing on agency alone runs the risk of presuming empowerment when, in fact, it does not.

We distinguish between intermediate achievements and ultimate achievements. The latter represent measures of nutritional status (for example, BMI and anaemia) that we seek to explain or influence. We identify a set of intermediate achievements that lie on the pathway to achieving the ultimate outcomes. These are specific to the different domains, discussed below.

\section{Domains of Nutritional Empowerment}

We consider three main domains as particularly relevant for nutritional empowerment - food, health, and institutions. These are consistent with the

\footnotetext{
5In the case of women's nutrition, it may well be the case that women may value directing resources to their children at the expense of their own nutrition. In this case the women have agency but this also points to the need to have resources to support the fulfillment of their own nutritional outcomes.
} 
UNICEF approach (1999) to understanding child malnutrition as resulting from underlying, intermediate, and immediate causes. Across each domain, we consider resources, agency, knowledge, and achievements. We also highlight paid and unpaid work as a cross-cutting factor that feeds into both food and health. These factors are inter-related in multiple ways. Adequate food and good health enable more productive, efficient and, possibly, more remunerative work (Dasgupta 1997). Income from paid work may give a woman greater autonomy and enable her to purchase better quality and more nutritious food, but a too strenuous working day (including both paid and unpaid work) may undermine health and increase the food/calorie intake needed to match energy expenditure (Leroy et al. 1994). In turn, ill health or a poor diet reduces the capacity to work and hence access to a main source of livelihood. Unpaid work, in terms of the time and care that goes into food preparation, or water purification, might make a direct positive contribution to nutritional outcomes by ensuring healthier meals. We introduce another sub-domain - fertility - that is relevant to a subset of people - women in the reproductive age. In each of the domains we describe the different dimensions of knowledge, agency, resources and achievements by which the WENI Grid (Table 1), is later organized.

\section{III.1. The Food Domain}

\section{Knowledge}

There is some consensus today that nutritional knowledge is the foundation for better diets, although its influence on actual intake may not be very strong due to a number of factors (Spronk, et al. 2014 for example). We draw from the Food and Agriculture Organization (FAO) definition: "Knowledge in the food domain refers to an individual's understanding of nutrition, including the intellectual ability to remember and recall food- and nutrition-related terminology, specific pieces of information and facts" (Fautsch Macías and Glasauer 2017. P:8). We include, in this domain, knowledge of cooking practices, of enhanced nutritional requirements of pregnant and nursing women and adolescent girls and the nutrient content of food.

Examples of knowledge as a limiting factor in nutritional empowerment come from our qualitative research in India and Bangladesh in 2016. Many 
women had misconceptions about the nutritional value of different foods and incorrectly believe that the most expensive foods are most nutritious. For example, in Bihar, some women believed that the most expensive nuts (e.g., cashews and almonds), were more nutritious than lower cost foods such as milk, eggs, and poultry. Sometimes, women allocated their meagre budget to these expensive foods thinking that these are needed for their families, ignoring locally available inexpensive options. Some women, believing there were no adverse consequences for mother and child, ate less during pregnancy to enable easier deliveries. Thus, even if their material and financial resources support better food intake during pregnancy, the absence of knowledge might override the potential positive impacts of resource availability.

\section{Resources}

Resources, structural conditions and practices that affect access to food encompass a wide range of factors. In the context of agricultural production, norms governing access or title to land and water; terms and conditions of both paid and unpaid work; and access to input markets, extension, and credit matter (Gomez et al. 2011; Pinstrup Andersen 2014).

However, literature on rural agriculture-nutrition linkages often presumes that individuals' access to land is the main source of their own food and livelihood. In many rural contexts, where the proportion of landless households is high or in tribal and coastal communities, households necessarily rely on common property resources and off-farm activities to earn for food. In some communities, for example in the hilly areas of Odisha, forest-based produce, plants and animals as also fish from water bodies are a crucial source of food (Lentz et al. 2017). The availability and access to these resources are shaped by seasonal factors, legal issues (restricting user rights) or social norms that might govern the use of these commons.

Both paid and unpaid work affect a woman's ability to access food as well as her need for food, largely via two channels, income and time. If the work is paid, the income a woman earns might increase her opportunity to purchase quality food. Energy expenditure associated with both paid and unpaid work is likely to influence her daily caloric requirement. Too much work, of all kinds, 
may not leave enough time available for preparing food, feeding and health care. As discussed earlier, there are trade-offs between these channels in terms of their effects on nutritional outcomes.

Whether the experience of paid work is empowering and translates into positive nutritional outcomes for the women concerned depends on the terms of such work including: the type of jobs women can access (given their skills) and the conditions and pay of those jobs. The terms of work can affect intrahousehold resource allocation and decision-making: for example, the extent to which a woman retains control over earned income, or earned in-kind food, and a say on how to use it. There is consensus in the empowerment literature that employment status matters (ILO 2017; Kabeer 2012). Work as unpaid contributing worker on the family farm or enterprise is unlikely to challenge women's subordinate position within the family or expand their opportunities. Either self-employment or wage work may hold out a greater promise of empowerment, but this depends on whether women engage in survival-oriented income-generating activities or in more remunerative and formal activities at the high end of the spectrum (Kabeer 2012). It may also depend on the location of work, with piece rate work within the home less likely to be associated with decision-making power than work outside the home (Kabeer 2000). Evidence from our field work suggests that self-employment in the form of small-scale artisanal work (e.g. making leaf plates in Odisha) or exploitative daily wage labour in agriculture (e.g., harvesting rice in Bangladesh at lower wages than men) might be the only paid work options available in the areas we visited, with hence little promise of positive effects on nutritional outcomes.

With regard to unpaid work, the emphasis of the feminist literature is on too much of it falling on women's shoulders. By burdening women physically and restricting their participation in paid work, training and community life, unpaid work can have a disempowering effect (Elson, 1991; Antonopoulos, 2009; UN Women, 2015). Restricted opportunities to earn a decent living and/or acquire new knowledge through training may in turn have a negative (indirect) impact on a woman's ability to enjoy a varied and nutritious diet.

The relevance of unpaid work to nutritional empowerment thus relates mainly to how taxing this work can be, especially when carried out in 
combination with other work. An improved understanding of women's time allocation and main causes of work burdens can allow us to identify possible interventions that address structural constraints (Kabeer 1999; Gomez et al. 2013; Pinstrup-Andersen 2014). For example, in some contexts, simply improving poor households' access to water infrastructure could itself contribute to women's nutritional outcomes.

Where markets exist, they could potentially serve as an arena for individuals to exercise their agency to procure food (or inputs for production). But these too are regulated by pricing rules reflecting unequal power relations and information asymmetries, which the literature points out are often exacerbated for women (e.g. Harris-White 2003). An absence of markets or imposed restrictions on movement can preclude women's agency to sourcing food. Even with the requisite knowledge and agency, external constraints such as these undermine the realization of desired nutritional outcomes.

Further, the ease and comfort of utilizing markets to access food and other resources may vary across and within households within the same communities. For example, markets are nearly always physically accessible in Bangladesh, but some women, often young married women, are not allowed to or are not willing to shop, although others, such as widows, often are. Other women are allowed, but only when accompanied by relatives.

Likewise, the state can often play a critical role in food provision. In India, for instance, wide-ranging food related schemes such as the public distribution system (PDS) for grains, pulses and edible oils, even fortified salt and flour can redress market access issues in remote areas providing a system that can potentially support women's food intake and free up resources to buy more diverse diets. Yet, a (implicit) subsidy on certain foods encourages consumers to purchase those foods at the expense of other, unsubsidized but more nutrient dense foods. As a result, people may achieve dietary caloric adequacy through the policy but may not achieve a diverse diet (see Narayanan and Gerber 2017 for examples of both these phenomena in India).

Food resources can be provided by civil society organizations or community based organizations too, as with collective food purchases by selfhelp groups in Bihar, India (Christian 2014). These institutions can be directly 
involved in food provision or be involved in providing inputs to support food production, kitchen gardens or creation, maintenance and conservation of common pool resources.

To the extent that resources also include structural conditions, the influence of cultural practices and social norms garner little attention in existing work, undoubtedly in part because they are challenging to identify and even more challenging to change. These norms and practices can inhibit a woman's ability to take the action she wishes. Such practices appear to be important drivers of continued undernutrition of women and children in South Asia (Ramalingaswamiet al. 1997).

Our formative research suggests that norms such as food allocation have a powerful and direct impact on food intake of individuals within a family (Lentz et al. 2017). Food distribution within the household and eating order are governed by a number of practices and norms that may overwhelm a woman's individual agency to be adequately and appropriately fed. We find that many women in Bangladesh, Bihar, and Odisha routinely eat last and take less. Our research also suggests that young women are often the first to give up food to ensure that other household members, such as children, their husbands, or their in-laws have enough (Lentz et al. 2017; Radimer et al. 1992). These norms can be deeply entrenched, even as women take on earning income. This finding, however, may in turn depend on the type of paid employment and civil society membership available to women in the villages we studied. Norms around food allocation and provisions, norms on who fasts and who eats the choicest foods (i.e., most nutrient-dense foods, such as meat) influence dietary patterns not only between women and men but also between women belonging to different generations. Further, in some communities, pregnant women may be most nutritionally at risk because they are encouraged to eat less to have easier deliveries or fast for sons.

These practices further extend to coping strategies that lead to poor nutrition. When food is scarce during lean seasons, it is usually women who cut down their food intake to ensure that men and children have enough on their plates (Lentz et al. 2017). Social customs generally do not adjust to support 
women's needs during crucial reproductive events in women's lives- pregnancy and breast-feeding, when nutritional requirements of women are substantially increased. Data from National Nutrition Monitoring Bureau (NNMB 2006) in India show that rural Indian women are not able to improve their diets during these critical phases when the nutrient requirements are at their peak. There is evidence from rural India that suggests that, of the children whose nutritional status improves over time, a significant proportion of them have mothers whose BMI declines over the same period (Rampal and Narayanan 2017).

\section{Agency}

Agency in the domain of food encompasses both implementation and executive agency in decision making over production, acquisition/procurement, and distribution of food; these are potentially empowering because any individual who has this sort of agency has greater likelihood of being able to feed themselves adequately. ${ }^{6}$ In cases where some household members take decisions without engaging with other household members, the excluded members' agency is undermined, and they are left with the resources resulting from the other members' decisions.

Decisions with respect to crop choices, which lands to use for what the most fertile, often being devoted to cash crops), management of kitchen gardens, consumption-sale of produce and control over earnings therefrom all matter for food access of the household at large, especially for those families that own or are able to lease land. Bhagowalia et al. (2012) report that increases in number of household decisions made by women is associated with greater dietary diversity, controlling for economic status. Decisions over how much to spend, what to buy, and where to buy and women's ability to do so are essential components of this domain.

\footnotetext{
${ }^{6} \mathrm{An}$ individual could of course use his or her agency to direct food resources to others. This is not necessarily viewed as disempowering, except when resource don't exist to support the individual's own nutritional status. At times it might be complex, however, to distinguish between authentic preferences and what Amartya Sen calls 'adaptive preferences', determined by a situation in which a woman adapts to certain unfavorable circumstances and internalizes others' norms around whom should be fed first. Any self-evaluation in terms of happiness or preferences will in this case necessarily be distorted (Sen, 1990)
} 
Access to paid work in the formal sector (e.g. clerical positions in local government, schools) can also contribute to greater agency on food decisions. This is not only because of a potential higher income that comes with it, but also because of better information and greater self-esteem, which might result from interacting with others in the workplace. Greater self-awareness could extend to decisions regarding food preparation, eating habits as well as a greater sense of entitlement to equal shares of food within the household.

While some of these aspects, such as decision making with respect to production, are covered in existing measures such as the WEAI, others such as agency around food acquisition and distribution remain neglected. ${ }^{7}$

\section{Achievements}

Intermediate achievements in the food domain are represented by two dimensions of food intake -food adequacy and dietary quality (represented by dietary diversity). Poor quality diet is now acknowledged to be a major cause of non-communicable diseases worldwide (GLOPAN 2017) and inadequate intake of nutritious foods is a well-established cause of undernutrition including micronutrient deficiencies (Gopalan 1996, James 1993). Nutritional outcomes are often measured at the household-level (e.g. household dietary diversity scores) even though individual-level measures are more appropriate (FAO-FHI 360 2016; Coates et al. 2010; Jones et al. 2013). When studies do address individual outcomes, most, though not all, tend to focus on child nutritional status rather than that of women (e.g., Smith et al. 2011). Focusing on the specific nutritional status of women helps to identify crucial possibilities for improving their life-chances and nutritional access.

\section{III.2. The Health Domain}

\section{Knowledge}

In the context of health, we focus on knowledge of practices around water and sanitation, endemic and epidemic/communicable diseases. These include awareness of the need to store and treat water appropriately, of water quality issues (arsenic levels in Bangladesh, for instance), of sanitation practices (use

\footnotetext{
${ }^{7}$ Recent extensions of the WEIA now include some aspects of food acquisition and distribution.
} 
and maintenance of toilets, hand washing), as also the consequences of poor sanitation and related practices. We also incorporate awareness of disease transmission and treatment (e.g. oral rehydration salts for diarrhoea), focusing on diseases that have strong links with nutrition, such as diarrhoea, malaria, and tuberculosis. Knowledge of clean cooking fuels and the consequence of indoor air pollution on account of use of firewood in indoor kitchens is also relevant in marginal contexts. Knowledge of various government schemes such as initiatives to promote the distribution of supplements during pregnancy is relevant as well, especially in contexts where general public health services are poorly functioning.

We found in our study that many women are often unaware of the healthrelated resources available to them, which could help them make strategic life choices. For example, in rural Odisha, some women we interviewed were unaware of the existence of the Anganwadis, which are child and mother health care centers. In contrast, other women were aware of them, but the centers were too far away to be a useful resource.

\section{Resources}

Access to clean water and fuel is often a tall order - as already noted women are burdened with work effort, which could be reduced with adequate physical infrastructure. The ease of access to these resources often varies by season. Likewise, women often do not have access to toilets - resort to open defecation and again walk long distances. Lack of safety is an additional problem. At the same time, young women often perceive having to go out as offering a certain kind of freedom (Coffey et al. 2015).

Affordable and quality healthcare is often a constraint in South Asia, contributing to high levels of morbidity. Accessibility to healthcare centres and hospitals include not just physical infrastructure but also favourable terms of access, including appropriateness of health staff and quality of service delivery. Specific government initiatives like distribution of bed nets, polio and Vitamin A campaigns, distribution of Iron and Folic Acid (IFA) tablets during pregnancy, are examples of government interventions that may be critical elements in the 
public health support structure as are subsidized health care, cash grants/insurance to incentivize health seeking.

While, as noted, women's heavy work burden can undermine their health, access to good forms of paid work, can improve resources needed for health, in terms of both greater availability of income and access to health facilities (e.g. when the law stipulates that these are provided by the employer). On the other hand, paid work, where occupational health and safety standards are not complied with, can negatively affect health and even fertility.

As with food, several gender norms may govern both women's health seeking behaviour and medical personnel's behaviour. Often, in rural South Asia, traditional healers/uncertified medical practitioners are the first service providers for women, while their husbands might seek more formal (and expensive) care elsewhere earlier or for less severe diseases. Many women in our qualitative study described these practices as fixed or difficult to challenge (Lentz et al. 2017).

Agency

To capture agency around healthcare, we interrogate the degree to which women contribute to decisions around investments in health and healthimproving assets and choices. This includes long-term decisions, such as the construction of a toilet, installing improved water sources, water treatment (fuel and stove) and purchase of critical items to preserve health. Thus, for example, while having access to toilets is treated as a resource available to women, where and when they have had a say in enabling such access (such as inputs into where to build WASH infrastructure and how to design them), counts as agency. Regarding short-term decisions, we consider the degrees to which women also have a say in health seeking for their own health and the health of their family. This includes questions of how they prioritize health seeking within their family. We find that intrahousehold differences in use of healthcare vary across households and across contexts (Lentz et al. 2017).

\section{Achievements}


We characterize achievements in the area of health as the ability to avoid common health risks by living and working in safe environments and practicing behaviours that will help minimize preventable diseases. The World Health Organization defines health as a state of complete physical, mental and social wellbeing and not merely the absence of disease or infirmity. However, for the purpose of the WENI Diagnostic Tool, we focus on whether women experience measurable adverse health determinants that are likely to impact nutritional status. These include self-reported morbidity, such as chronic and acute disease, shocks and injuries, and perceptions of health. As intermediate achievements, current practices around washing hands and toilet use, and also alcohol, smoking and drug use are relevant for individuals.

Ill health can inhibit the absorption of nutrients; similarly, diseases transmitted due to poor water and sanitary health can also hinder a person's nutritional status. By including achievements in the domain of health, we capture pathways key to nutritional outcomes and can establish the degree to which such pathways contribute to fully realized nutritional outcomes that reflect meaningful choice.

\section{III.2.1 The Fertility Domain}

We hypothesize that the domain of fertility - a subset of health relevant only to women between the ages of 15 and 49 - is a critical aspect of nutritional empowerment. As with other domains, the dimensions of empowerment knowledge, resources, agency, work in complex ways to determine achievement.

\section{Knowledge}

There are several types of support for women who are considering becoming pregnant, are pregnant, or have recently delivered. For example, in India, the Integrated Child Development Services (ICDS) program, which provides food supplementation to pregnant women, and a maternity entitlement benefit scheme are some of the public funded schemes to help pregnant and lactating women meet their dietary requirements. Yet, not all women have knowledge about these support schemes. 


\section{Resources}

The availability and functioning of public sector support programs and medical facilities vary across and within communities and could be important resources for both fertility decisions and pre- and post-natal care. The Integrated Child Development Services (ICDS) in India, for example, is currently a legal entitlement. However, there are large disparities in the effective implementation and utilization of programs such as ICDS. The overall impact of these schemes in enhancing women's nutritional status has not been significant. In India only 17\% of rural women availed full antenatal care. ${ }^{8}$

\section{Agency}

Women face a series of fertility and child-related decisions that can affect their own nutrition as well as the nutritional status of their children. A key issue is role of women's control over fertility decisions. Low age at marriage, short birth spacing and many children continue to be critical factors influencing the health of young women and the birth weight of children. Women have varying degrees of agency over decisions on when and how many children to have, and on contraception use. Further, for those who have children, their say in their diet during and post-pregnancy through the nursing phase varies. Some women have agency to negotiate with the program functionaries and assert their right of receiving the food aid. Women able to assert their rights are better able to enhance their dietary intakes as envisaged by these programs.

\section{Achievements}

A number of variables can represent achievements in the fertility domain. Age at first marriage, first pregnancy, spacing and number of children, and child mortality are all known to be associated with women's nutritional status (in a statistical sense). Some of these are well recognized (Engle et al. 1999).

The domain of fertility is best considered a "stand-alone" component of nutritional empowerment and of the WENI Diagnostic Tool. Fertility is limited to

\footnotetext{
${ }^{8}$ As reported in the National Family Health Survey (NFHS-3) India 2005-06. International Institute for Population Sciences Deonar, M., India. Available from: http://rchiips.org/NFHS/pdf/NFHS4/India.pdf
} 
a subset of the population, which means that comparisons between men and women, as well as for older and younger women are not possible. In the WENI Grid, we provide results related to this subdomain for women in the reproductive age. This enables us to make intra-group inter-person comparisons, but not across generations or sexes. ${ }^{9}$

\section{III.3. The Broader Institutions Domain}

Beyond the norms and cultural practices that influence an individual's food, work and health resources that are captured in their own domains, the domain of broader institutions refers to legal rules, legal pluralism, and societal and community norms that influence the position of an individual. This domain has a complex relationship with other domains. Perhaps here, more than in any other domain, the lived experience could be substantially different for men and women, notwithstanding the legal provisions.

Here, we restrict the ambit of institutions likely to be related to nutritional empowerment to those that might not necessarily operate through the food and health domains.

Access to media and the mobile phone represent key channels to greater general awareness. Participation in the public sphere, such as whether women can vote, can stand for election or can speak comfortably in public can lead to greater sense of gender justice (Kabeer 2011). This may not be achievable for all women; some women (e.g., widows or unmarried women) in some communities may face taboos against becoming members of groups, attending public meetings, interacting with officials, and moving freely within and beyond the village and have prescribed dress codes like the use of a veil. We also consider issues such as marital parity, represented for example, by differences in education levels, differences in age between spouses, and a woman's age, and household structure more generally.

We are also interested in opportunities individuals have for collective action. Our formative research indicates that these present opportunities for women and men to make demands on the state to secure resources that might in

\footnotetext{
${ }^{9}$ For the WENI index, we exclude the fertility domain because the goal of the index is to enable inter-group comparisons.
} 
turn promote nutrition. Examples include seeking land rights in Bangladesh, and community-wide protection of common property resources. There is some evidence that suggests that stunting was likely to be lower for children of women who participated in group initiatives including empowerment and knowledge programs, early child care programs, and parent teacher associations (Smith et al. 2011). We believe this could well be the same for women's nutritional status.

We also aim to capture aspects of the larger contextual condition conducive to nutritional empowerment, especially support systems that are available to women when they are most vulnerable. What recourse do women have to assert rights or seek remedies, legal or otherwise? Are there then community institutions available and how far are they supportive of women? Are there civil society actors who mediate or facilitate such attempts or is it largely their parental families who offer fallback options? These various institutions represent the support structures available to individuals.

A number of constitutional amendments made for women's social, economic and political benefits in India have been helpful as indicated by some improvement in women's empowerment indicators in the NFHS surveys. These gains are likely to have contributed to the progress in reducing undernutrition in women from India (NFHS-4). 


\section{Women's Nutritional Empowerment and the WENI Grid: key points}

- Defining women's nutritional empowerment is important because policy interventions aimed at increasing food production and promoting women's economic participation may overlook constraints and trade-offs that prevent rural women from achieving well-being and good health even if they engage in income-generating activities.

- Nutritional empowerment is the process by which women acquire the capacity to be well fed and healthy, in a context where this capacity was previously denied to them. It involves acquisition of knowledge, economic and social resources, as well as agency. These dimensions are inter-linked.

- The WENI grid constitutes a systematic way of identifying the multiple factors enabling or hindering this empowerment process for rural women, and hence facilitate well-targeted policy interventions. The grid includes a range of likely determinants in the domains of food, health, and institutions, with paid and unpaid work as cross-cutting factors.

- Contributing factors in the domain of food include: women's knowledge of nutrient content of food, nutritional requirements at different stages of the life cycle (e.g. during pregnancy) and cooking practices; terms of access to land and common property resources (as sources of food) and paid work (as potential source of both income and agency); availability of both markets for food and public provision of food; family norms about eating.

- Contributing factors in the domain of health include: knowledge of WASH practices as well as awareness of disease transmission and treatment, awareness of public health services, total workloads as well as paid/unpaid work ratios, availability of WASH infrastructure, quality and accessibility of health facilities (to also include facilities for pregnant and lactating women), decision-making power regarding fertility (when relevant), health-seeking and time-use.

- Contributing factors in the domain of institutions include: media access, acceptance of women's participation in public life as well as safety of public spaces, extent of hierarchy in household structures, opportunities for collective action, availability and effectiveness of legal support specifically for women. 


\section{Nutrition and Empowerment Diagnostics (NED)}

Operationalizing nutritional empowerment that correlates with nutritional status involves two formidable challenges. First, measuring empowerment is far from straightforward (Kabeer 1999; Robeyns 2003; Gates 2014). As Kabeer (1999) has argued, some indicators that are intended to capture empowerment fail to do so. There is also a view that it is not always desirable or easy to quantify what is essentially a complex process. ${ }^{10}$

At the same time, a rich tradition of empirical quantitative work has generated as many as 121 unique indicators of empowerment in the context of studying its influence on nutritional outcomes (Pratley 2016). Most of these measures of empowerment are typically confined to representing aspects for which data are available and few surveys collect data to represent empowerment as it is articulated in the empowerment literature.

A second challenge is the wide range of factors that collectively influence nutritional status. The effort of identifying precise relationships between empowerment and nutritional outcomes becomes complicated very quickly. In such situations, indices can be valuable tools to understand concepts that are complex and multidimensional. Despite their recognized limitations, notably the loss of detail (Meinzen-Dick 2013), they remain useful ways to aggregate information and communicate findings to initiate policy dialogue and discussion.

Notwithstanding these challenges, we believe that the conceptualization of nutritional empowerment itself and the attempt to measure it can (a) clarify our ways of thinking about the socio-economic contexts that shape nutrition outcomes, differently or not, for women and men (b) serve as a basis or tool for generating nutrition and empowerment diagnostics (NED) in the same vein as economic growth diagnostics proposed by Hausman, Rodrik and Velasco (2009), and (c) (hence) support efforts of policy makers to address critical gaps in order to promote nutritional security and health, specifically of women.

\footnotetext{
${ }^{10}$ Challenges associated with generating an empowerment index, such as how to aggregate and weigh factors, have been discussed in detail relating to the development of the WEAI and, related to WENI, are discussed in a forthcoming paper (e.g., Alkire and Foster 2011; Alkire et al. 2012).
} 
There is more than one way to operationalize our WENI grid. One approach is to use survey data to quantify elements in the WENI Grid, score each domain-dimension (Table 1) and obtain a scorecard of nutritional empowerment, allowing the identification of elements where there is least empowerment. This scorecard can be the basis for constructing an index, with the WENI aggregating the constituents of the WENI grid into a metric that would then reflect how empowered women are in the realm of nutrition. While recognizing that empowerment is a process and the pathways to empowerment are ridden with obstacles, a scorecard or index allows us to check progress relative to milestones on the path to empowerment. We are pursuing this approach in ongoing work, which is forthcoming. Here we focus on a second approach, in which we use the WENI Grid itself as a tool to generate nutrition and empowerment diagnostics (NED).

That is, the WENI Grid can be used as a heuristic device to make assessments of how conducive-to-empowerment an individual's specific set of structures and circumstances is. The rest of this section focuses on generating NED. It is possible to use the WENI Grid to identify binding constraints in a specific context. To the extent that (nutritional) empowerment is a process and the constituent elements need to work in tandem, the WENI Grid provides a way to identify obstacles in the pathway to empowerment and prioritize strategies to clear these paths. In this exercise, we adapt the Hausmann, et al.'s (2009) growth diagnostics and illustrate with an example from India.

The Hausmann-Rodrik-Velasco (HRV) growth diagnostics offers an approach to identify key focal areas for policy attention. The HRV diagnostics is motivated by the fact governments often face a long list of issues that need to be addressed but have "administrative and political limitations." In this context, "policy-making capital is better deployed in alleviating binding constraints than in going after too many targets all at once." A long list of everything that needs to be done or, as they term it, 'wholesale reform', is often not feasible.

Under HRV, a government aiming to achieve the "biggest reform bang for the buck", could release binding constraints by focussing on a few effective areas to address, when resources, political capital of financial resources are scarce. 
These binding constraints therefore offer the most effective opportunities for intervention or reform. In the context of nutritional empowerment, it could be the case, for example, that although women might suffer from unequal intrahousehold decision making, the absence of basic water and sanitation might in fact be binding constraints that drive poor nutritional status of women - say, for example, through increasing the unpaid work or energy expenditures of women. In this case, limited financial resources might be best prioritized for such infrastructure. This approach would also take into account the fact these constraints and hence the policy strategies that are optimal or most productive may not be the same across contexts.

There is a danger that this approach might make the analyst/policy maker lose sight of other equally important factors contributing to women's nutritional empowerment, for example changes in gender norms at the household level. For this reason, this approach should preferably be combined with focus on how to achieve improvements in each domain and dimensions.

A difference between the WENI index and the NED approach is that indices presume substitutability across elements, so that shortcomings or a deficit in one can be compensated for better scores on another element. In the diagnostic approach, domain-dimensions in the WENI Grid are treated as complements rather than substitutes, which might be more helpful in fostering a holistic approach to policy. Further, while the index can be computed for individuals, NED is for an aggregate and higher unit of analysis.

\section{The Methods}

HRV, in their original articulation proposed a decision tree approach to identify these binding constraints. ${ }^{11}$ In the context of nutritional empowerment, the goal is to identify which constituent elements of the WENI grid offer opportunities for intervention to improve women's nutritional outcomes. Ideally, the scope of analysis is at the relevant administrative unit so that findings are usable by those with capacity to make policy, such as district, state or country

\footnotetext{
${ }^{11}$ Later versions represent a more cohesive approach to conducting these diagnostics, addressing criticisms of the original version.
} 
policymakers. In what follows, we direct readers on how to conduct diagnostics using the WENI Grid.

Take, for instance, a sub-national unit in India, say a state, where the prevalence of thinness / undernutrition as represented by women's BMI $(<18.5)$ is very high. The WENI GRID supports the identification of the drivers of why women fare so poorly in this state (see Table 1). First consider the intermediate achievements and ask: Among the different domains - food and health (including fertility, if relevant), which intermediate outcomes are poor in ways that could result in poor BMI? If, among the cluster of intermediate outcomes, there are compelling candidates in terms of poor performance, it is useful to then move along that domain, using the logic of a decision tree, and identify which dimension(s) might be a weak link. In other words, within the domain of health, is knowledge, agency or resources, or some combination of these the major drivers(s) of poor achievements?

It is conceivable that the state has very promising or strong scores /milestones on some of these dimensions and not of others. Such cases require 'reasoned intuition' to see if there are tradeoffs across dimensions and whether some dimensions overwhelm others. For example, if knowledge and awareness levels are very high with respect to health but the target area has poor health infrastructure, then it may perhaps be the case that health resources are the binding constraint. Even within a specific domain-dimension it may be the case that awareness of WASH is high but awareness of endemic diseases is low.

The idea that one starts with the intermediate achievements and focuses on the dimensions within a domain should not preclude the possibility that some dimension in another domain could also simultaneously be a binding constraint. ${ }^{12}$ In other words, within that domain, the intermediate achievements may not appear to be an issue. For example, intermediate outcomes on the fertility domain may be very poor, but those of morbidity and related health outcomes may be good. Yet, it is possible that health resources also influence

\footnotetext{
12 This is one critique of the original form of growth diagnostics - that the decision tree analogy implies that once you are in a node in one branch, the relevance of all nodes in other branches become irrelevant. In our formulation, the Grid allows us to start anywhere and cover the entire Grid. Interestingly Hausmann et al. (2008) propose a "matrix" eventually to keep track of the various potential causes to help systematic diagnosis.
} 
access to resources that are specific to fertility. In this sense, one is advised to pursue the branch of the tree that seems most likely to help identify key constraints, but without neglecting the other branches.

Further, among the set of intermediate achievements, some could indicate that the domain related to those achievements is not the source of a problem whereas another domain is. For this reason too, it would be advisable to eventually investigate the entire WENI Grid.

\section{An Illustration}

As an illustration of how nutrition and empowerment diagnostics can be conducted using the WENI Grid, we use examples from Indian states to identify binding constraints that frustrate the achievement of women's empowerment and nutritional status - here represented by BMI of ever-married women between the ages 15 and $49 .{ }^{13}$ In the absence of survey data that represent all the elements of the WENI Gird, we use the third edition of NFHS data (2005-06). Relative to other available Indian surveys, NFHS most populates the Grid. We map survey questions to the WENI Grid (Appendix Table 1). We choose the six states purposively to represent two well-performing states (Kerala and Tamil Nadu), two states that have mostly lagged behind other Indian states (Uttar Pradesh and Bihar ${ }^{14}$ ) and two turn-around states (Odisha and Chhattisgarh) that have made impressive strides in the context of women's nutrition (as well as of children), but still lag behind Kerala and Tamil Nadu (Figure 1). Chhattisgarh and Odisha are two states that fared worse than UP and Bihar in 1995-96 but now do better with respect to BMI for women. To unpack the Shapley decompositions ${ }^{15}$ for UP, we compare UP against the remaining five states.

\footnotetext{
13 In this version, we include pregnant and lactating women, using binary variables to control for these in the regression.

14 Both the UP and Bihar were bifurcated after the first NFHS round. They may have "lost" the somewhat better performing parts of their states, which became Uttarakhand and Jharkhand, respectively. This bifurcation could contribute to the observed worsening of nutritional outcomes for women in these states between NFHS-2 and 3. However, their status as "lagging", based on NFHS 3 and 4, relative to other states, remains. When NFHS-4 micro-level data become available, it would be useful to redo these analyses between NFHS-2,3\& 4. Currently, we only have access to state-level findings for NFHS-4.

15 The Shapley decomposition is a theoretically sound procedure for decomposing the total explained variation in nutritional outcomes into the sum of partial R-squared where each additive component represents the contribution of an individual regressor to total R-squared. The Shapley value has its origins in cooperative game theory that seeks to find a way to
} 
Figure 1: A Comparison of BMI for rural women in Indian States (1995-96 to 2015-16)

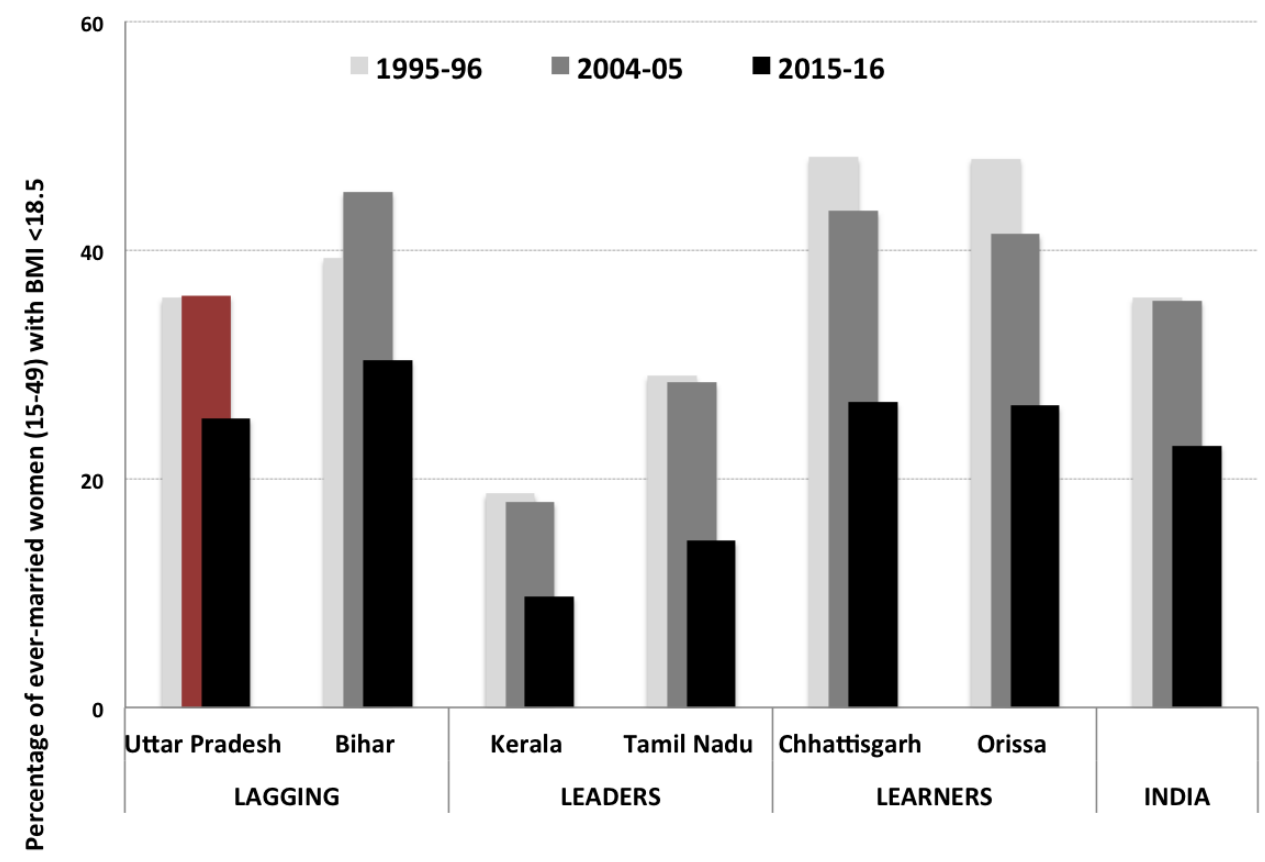

Source: Data from NFHS-2,3\&4; The terms lagging, leaders and learners have been used in the context of implementation of food subsidy programs.

While Tamil Nadu (TN) and Kerala have historically been better performers and have managed to continue to improve, it is interesting to conduct diagnostics for lagging states like Uttar Pradesh (UP) and Bihar. ${ }^{16}$ Although we present decompositions for all six states, we specifically focus on UP in2005-06 for NED.

We begin by asking why UP has such a high proportion of women who are thin (BMI <18.5). UP tends to do poorly on virtually every indicator - be it economic or social indicators. Policy-makers who want to address nutritional empowerment thus face a long list of issues that need to be addressed. NED can

distribute the total gains from a game fairly. The Owen value is an extension of the Shapley value for so-called "cooperative games" with coalitions. In the context of a regression, the coalition is essentially a group of regressors and the contribution of specific groups of indicators to total Rsquared can be ascertained. In the context of the WENI grid, each cell or domain-dimension combination in the grid serves as a coalition and the relative contribution of each of these can be ascertained to identify key priority areas for policy intervention. This approach is an improvement over other decomposition methods. For more details on how to use this approach, see Narayanan, et al (2017).

${ }^{16}$ The latter exercise relies on cross-section data for NFHS 2005-06 merely as an illustration. Ideally, the diagnostics need to be conducted using current data (for instance, 2015-16 data from NFHS-4) to be able to make policy recommendations. 
help to identify the focal policy areas that offer large returns. We use the Grid to work back into possible causes. ${ }^{17}$

\section{Data requirements}

To be able to conduct a diagnosis, one needs to draw data from a variety of sources. Survey data, regressions, qualitative research, and anecdotal information can be combined to create a coherent causal story. Hausmann et al. (2009) advocate for pragmatism with respect to the kind of evidence we use. They also note that diagnostic approaches are iterative in nature. ${ }^{18}$ A specific survey that captures comprehensively the elements of the WENI Grid would be ideal to conduct NED. Nonetheless, existing secondary data can be used effectively as tools for diagnostics, as we illustrate, with the Demographic and Health Surveys (called National Family Health Survey - NFHS in India). Our current effort has been to identify specific measures for each constituent element in the WENI Grid from the secondary data. ${ }^{19}$ NED can also be combined with certain historical and contemporary data from secondary sources as well as qualitative research.

Where reliable data exist, this diagnostic approach can be built around a decomposition analysis that identifies the contribution of each of constituent elements of the WENI grid to nutritional outcomes. We recommend the use of Shapley-Owen decompositions. A high Shapley value means that the specific domain-dimension is a key influencer of nutritional outcome; at the same time, to determine if it is a binding constraint it is important to examine whether there is scope for further investments in this domain-dimension and the direction of influence of the various components. If health resources are key influencers and

\footnotetext{
17 One could also start from low-scoring domain and dimension specific elements to build a theory of change Supposing one is interested in knowledge interventions - say in the domain food, because there is evidence or experience suggesting that intended beneficiary group scores low on nutritional knowledge. Examining the Grid, we could ask to what extent would one expect expanded nutritional knowledge to contribute positively to ultimate outcomes? We could then ask a series of follow-up questions, such as do women have agency and access to resources and structural conditions to support the translation of this intervention into improved nutritional status? And are there tradeoffs operating through the interactions of the different domains and dimensions that might thwart this translation?

18 Diagnostics use a combination of data and theory, and deduction and induction; these diagnostics can also identify context-specific underlying models (Hausmann et al. 2009). ${ }^{19}$ Later, we will devise data collection instruments to capture these elements to be able to score these to get at an index, as WEIA does. These scores themselves can be used to aid diagnostics.
} 
the state has poor health infrastructure and access, health infrastructure and access are most likely a binding constraint and therefore a policy target. Alternatively, the Shapley contribution (and the strength of association) may be low for a domain dimension, but it could be on account of a lack of variation across the state.

Further, as Hausmann et al. (2009) propose, a fruitful approach is a comparative perspective - if one element is identified as crucial in one context (an Indian state) to what extent is this element consistently important in other states? If not, we can ask, why might that be the case? On the other hand, if the element is weak or absent, but the ultimate outcomes are satisfactory, what might be the reasons for that? Using a combination of these two types of comparisons, it is possible to refine the diagnostics to better identify key constraints.

The explained variance, or R-square, in our model is about $23 \%$ for UP, in keeping with other estimates of nutritional status in India (Headey et al. 2012). The Shapley decomposition for UP shows that Institutions (14.7\%, 14 variables), and Health-Resources (14.5\%, 28 variables) are the two domain-dimensions of the WENI Grid that most explain the variation in BMI, as measured by R-square. Table 2 presents the Shapley-Owen decomposition by domain-dimension by state. Appendix Table 1 includes a list of attributes included in each domaindimension. Fertility-Resources (7.7\%, 24 variables) and Health Knowledge (5.9\%, 8 variables) are the other major factors. Figure 2 shows the contribution of the different constituent elements of the WENI Grid. With these priors, we proceed sequentially to identify the key constraints. 
Figure 2: Shapley-Owen decomposition by WENI Grid domain-dimension (Uttar Pradesh, BMI for ever married rural women 15-49 years, 2005-06)

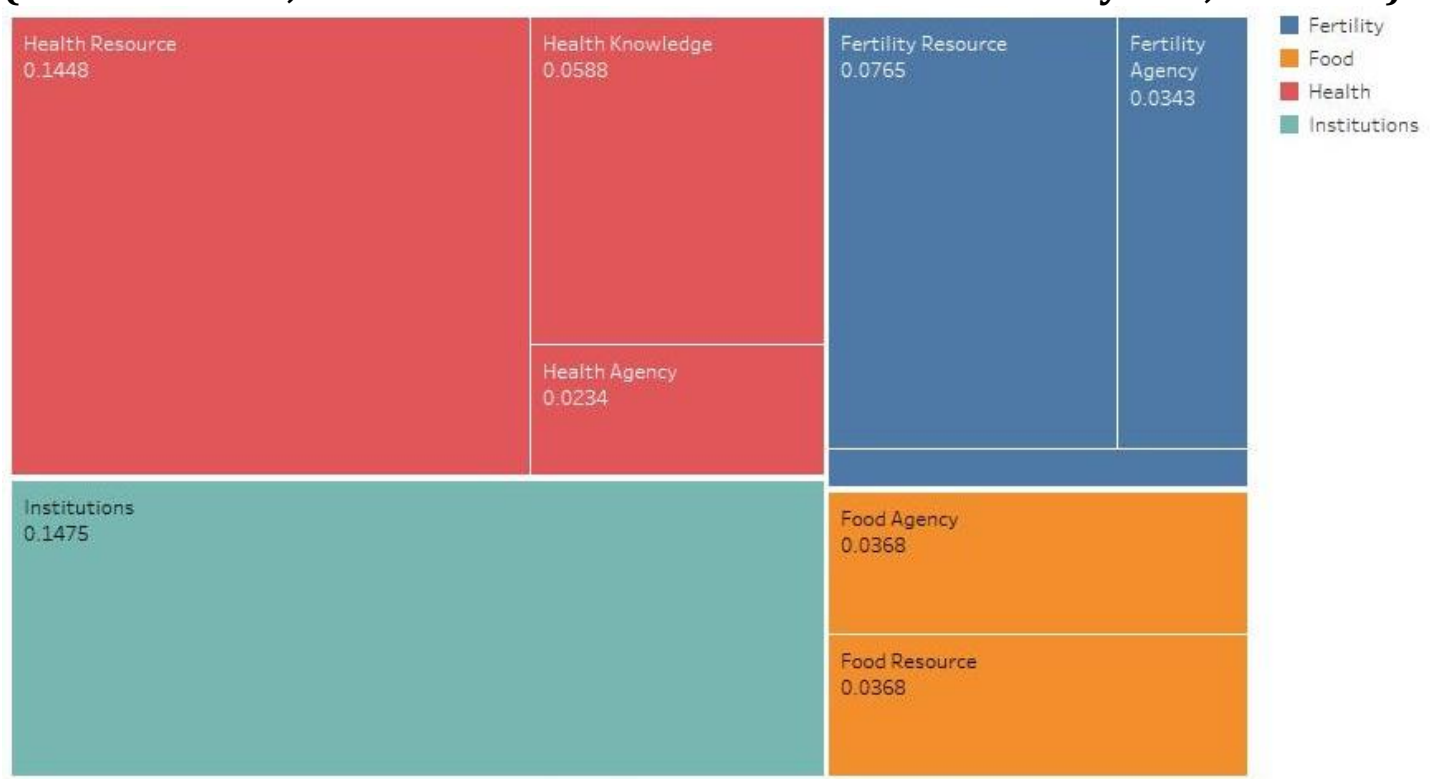

Domain-Dimension and sum of R-Square. Color shows details about Domain. Size shows sum of R-Square. The marks are labeled by Domain-Dimension and sum of R-Square.

We use the WENI Grid to examine intermediate achievements on the domain of food, health and fertility. Within the food domain, UP does not appear to fare poorly on food adequacy - the average consumption per consumer unit in UP are within the recommended daily allowance for Indian adults. 20 Disaggregated daily allowance data are not available; it might be the case that women consume less relative to men. That said, calorie consumption in UP is higher than other states that have a good record of women's BMI, including TN. However, women in TN have a much better quality of diet. In UP, the proportion of women who have consumed fruits at least once in the past week is $24 \%$; $13 \%$ consumed eggs in the last week and $11 \%$ consumed fish/chicken meat. In contrast, $60 \%$ of women in TN ate fruits at least once in the reference week; the proportion of women in TN who had eggs and fish/chicken meat are five times that of UP. Interestingly, Shapley decompositions suggest that food resources in TN contributed much more to explaining women's BMI in TN than they did for UP. ${ }^{21}$ (See Appendix Table 1 for list of food resources included). Dietary diversity

\footnotetext{
${ }^{20} 2743 \mathrm{Kcal}, 82.1 \mathrm{gms}$ of protein and 46.8 gms of fat per consumer unit per day. http://mospi.nic.in/sites/default/files/publication_reports/513_final.pdf

21 This is also the case for Bihar, where resources supporting the access to food are influential in determining BMI.
} 
is therefore poor in UP but does not seem to play a critical role in determining BMI, either due to the absence of variation across individuals or because it is not a strong determinant of BMI.22

On the health domain, the incidence of acute and chronic illness is high in UP relative to several other states $12.6 \%$ and $7.4 \%$, although that of diseases like malaria, kalaazar, etc. are low. States such as Odisha, Bihar and Chhattisgarh have a much higher incidence of these latter. ${ }^{23,24}$ Examining the possible reasons for poor health outcomes of women further, it is evident that health-resources are potentially a significant constraint. It is well known the public health facilities function poorly in UP and this is reflected in the high proportion of people who use private medical care. Further, the quality of private medical care is also reported to be poor. ${ }^{25}$ More people in TN and Kerala access public health systems and the contribution of health resources to explaining BMI is similarly large in these states as well. While drinking water access does not seem to be a key constraint in UP $(60 \%$ have water on their premises and $35 \%$ can access it within 30 minutes and 92\% have improved sources), only $2 \%$ treat water before drinking (and indeed knowledge of water treatment is poor). Sanitation is a problem as well, with less than $10 \%$ having access to private improved toilets. Close to half still use wood as cooking fuel, implying a burden on women who fetch the firewood. Only a fifth have a dedicated kitchen. Around 97\% use open fire without chimneys, exposing women who cook to indoor air pollution. Health-agency is also somewhat limited. The proportion of women who have freedom of movement to health facilities (among others) and a role in decisionmaking on own health, UP fares poorly compared to all the other five states - a point discussed later.

\footnotetext{
22 We also analyze the relationship between the ultimate outcome and the intermediate outcome as well as intermediate outcomes and the domain-dimensions of the WENI Grid. These are not reported here.

${ }^{23}$ Acute illness is defined as a disease that has an abrupt onset and is generally short-lived. Chronic illness is a human health condition that is persistent and lasts longer than usual. In most cases, it cannot be cured completely.

24 These data are for 2010 on onwards from the Annual Health Surveys reported in http://www.censusindia.gov.in/vital statistics/AHS/AHS report part1.pdf. Interestingly, in UP the incidence of acute illnesses has remained the same even in recent years and that of chronic illnesses had increased to $10.6 \%$ in $2012-13$.

${ }^{25} \mathrm{http}: / /$ everylifecounts.ndtv.com/how-healthcare-system-of-uttar-pradesh-failing-its-people5569
} 
Intermediate achievements on the fertility domain are similarly dismal. The total fertility rate for women in rural UP is 4.1 and has changed little since 1998-99. Women in UP continue to have more children than in other states. At the time of the survey close to $16.3 \%$ of the women aged 15-19 were already married and the median age at first birth is 19.1 years for women between 15-49 years. On all of the fertility resources, UP scores poorly with only over half having institutional birth or with assistance; 8.7\% ha consumer IFA for 90 days or more, and only a quarter had had at least three antenatal visits before last birth.

We now examine the domain of institutions, conceptualized as overarching factors (such as freedom of movement, financial inclusion of women, participation in political processes, etc.) that influence BMI through multiple channels. UP fares poorly relative to other states in each of these sphered. Less than a quarter of women are allowed to go alone to the market, health center and places outside the village. This is compared to, for example, $54 \%$ in TN. The proportion of women who participated in decisions on the following four domains - health care, major household purchases, daily purchases for home needs, and visits to her family or relative - is just over a fifth in UP, compared to close to half in Tamil Nadu and Kerala. Women's knowledge of microcredit programs and access to loans is very low in UP (14.1\% and $0.4 \%)$ compared to TN, for example, where these are $79 \%$ and $13.4 \%$ respectively.

In UP, as in Bihar, only $15.07 \%$ and $17.5 \%$ of women work for cash. In Chhattisgarh, women employment is high, but only $44 \%$ work for cash. In contrast, in Kerala, although 30\% of all women work, a majority - 91\% - of those working work for cash. Close to $50 \%$ of women in TN work and $90 \%$ of these women earn cash. These different patterns of work participation and earned income have significant association with the ultimate outcomes. ${ }^{26}$

It appears that in the case of UP, it is not the domain of food, but health, and in particular health resources, that appear to be an area for policy action. Institutions, which are distal factors, are important for long-term action, but in terms of bang for the buck, it is likely health resources need attention. A useful exercise would be to repeat this analysis for recent data to be able to understand

\footnotetext{
${ }^{26}$ http://eci.nic.in/eci_main1/SVEEP/VoterTurnoutHighlightsLokSabha2014.pdf
} 
the drivers of change over time. Existing evidence suggests public programs in TN and Kerala too work much better in comparison to UP, or for that matter Bihar. Much of the improvements in women's nutritional status and child stunting in Chhattisgarh and Odisha are attributed to improvement in public health systems and in social safety nets, especially food based programs. An extension of the analysis to 2015-16, when such data are available, would help diagnose whether failure to invest in these is indeed the cause of UP's lacklustre record. It would be essential too to examine other outcomes such as anaemia that might likely be associated differently with the WENI domain-dimensions for instance, with the food domain perhaps rather than fertility.

The dominance of the resources dimension across domains in terms of contribution to explaining nutritional outcomes is instructive (Table 3 and Appendix Table 1). Admittedly, the NFHS does not capture all the aspects of agency and knowledge outlined in the WENI Grid, but its contribution to explaining BMI seem somewhat limited. It is interesting however that knowledge and agency contribute the most in explaining BMI in Kerala and Tamil Nadu, respectively (results available upon request). It is possibly indicative of synergies, more generally, between knowledge, agency and resources - that in the presence of resources, the contribution of knowledge and agency could be substantial. Consistent with the UP findings, across the other five states too, the health domain seems to be the biggest contributor and food the least (Table 4). This reflects recent emphasis on water, sanitation and hygiene as crucial for nutritional outcomes.

The NED for UP describe above is a very simple illustration of the approach and can be further developed and enriched. This exercise also illustrates the heterogeneity and differences across states, as is evident from the Shapley decomposition exercise. This exercise also points to the ways that NED can support decision makers to identify which interventions will be most effective. Our ultimate aim is for the WENI index and NED approach to complement each other and to be used sequentially. Applying the WENI index can support the 'diagnosis' of disempowerment and NED can identify the causes of disempowerment / constraints for achieving empowerment. 


\section{Nutritional Empowerment Diagnostics (NED): key points}

- NED uses information organized in the WENI Grid along domains (food, health and institutions) and dimensions (knowledge, resources, agency and intermediate achievements) to generate nutritional diagnostics in the same vein as economic growth diagnostics.

- It is a tool for identifying binding constraints in the pathways of nutritional empowerment and prioritize strategies to clear those pathways among the range of policy interventions available, given limited financial resources.

- It uses the logic of a decision tree to investigate the cells of the WENI Grid. The idea is to start with the domain where intermediate achievements score the lowest, and focus on the dimensions within that domain. This, however, should not preclude investigating dimensions in yet another domain that could also indirectly constitute binding constraints. It is best to conceive this as an iterative process.

- NED captures broad institutional and environmental factors and can be computed for a district, state or region (but not for specific women or men). Ideally, the level of analysis is chosen so that findings can guide those with capacity to make policy, such as district, state or national-level policymakers.

- The ultimate aim is for the WENI (index) and NED approach to complement each other and to be used sequentially. Applying the WENI index can support the 'diagnosis' of disempowerment, and NED can identify the most binding constraints for achieving empowerment.

- A holistic approach that uses a variety of sources and combines NED with qualitative studies as well as aggregate measures of individual nutritional empowerment (such as WENI) is highly recommended.

\section{Conclusion}

The analytical framework and diagnostic tools developed in this paper are motivated by the wish to contribute to a shift in thinking and policy practice regarding gender dimensions of nutrition and the full realization of women's right to food. Governments have renewed their commitment to both gender equality and improving nutrition for all through their endorsement of the 2030 Agenda for Sustainable Development and put particular emphasis on leaving no one behind.

This paper has proposed a systematic approach to identify and prioritize policy interventions to improve nutrition of rural women and girls, with special attention to the most disadvantaged. It contributes a shift in thinking about women's economic empowerment by introducing a new emphasis on 
empowerment in the sphere of nutrition. It is hoped this emphasis will help researchers and policy-makers alike to pay greater attention to the fact that 'economic empowerment' in the narrow sense of participating in incomegenerating activities and greater decision-making on productive resources does not necessarily translate into better nutrition and health for the women concerned. Thus, there is a need to consider a broader set of factors and constraints when designing and implementing programs and policies aimed at gender equality. The emphasis on increasing women's capacity to secure nutrition for themselves constitutes also a contribution to the notion that women's empowerment is an important end in itself. This is especially relevant in the field of agriculture and nutrition, where advocacy for women's empowerment continues to be largely predicated on instrumental grounds related to the argument that it has payoffs in terms of children's welfare and/or agricultural productivity.

The paper contributes to policy practice by offering a range of tools to identify and most effectively target policy areas for improving nutritional outcomes of rural women and girls (NED), and/or to monitor the empowerment potential of specific agricultural interventions on the ground (WENI proper). To this end, the present paper outlined the constitutive elements of the WENI Grid, our main analytical framework, which carefully lays out a comprehensive set of factors contributing to women's nutritional empowerment and elaborates on their likely pathways and interactions. It then offered options for operationalizing the framework in a series of steps. We argued that the WENI Grid could be used as a basis for a number of practical tools to inform policy, either at the macro-level of state/district policy-making or at the micro-level of specific program implementation.

To illustrate, in the last section of this paper we focused on nutritional empowerment diagnostics, which we called NED, and proposed a systematic approach to identify areas that would be the highest-return policy targets in terms of improving nutritional outcomes. By applying Shapley decomposition techniques to the analysis of WENI grid components, we demonstrated how varying nutritional achievements of women in six states in India are related to specific binding constraints. For example, our NED application to the state of 
Uttar Pradesh suggested that programs aimed at addressing material resource constraints are likely to have the largest impact on women's BMI, relative to addressing gaps in other dimensions.

By giving careful consideration to the multiple dimensions of empowerment, and moving beyond conceptualizations exclusively based on individual decision-making and/or specific spheres, we can better understand the linkages between women's empowerment and their nutritional status. 


\section{References}

Agarwal, B. 2001. "Participatory Exclusions, Community Forestry, and Gender: An analysis for South Asia and a conceptual framework." World Development. Vol. 29, No. 10, pp. 1623-1648.

Alderman, H. Chiappori, P., Haddad L., Hoddinott, J., and Kanbur, R. 1995. "Unitary versus Collective Models of the Household: Is it time to shift the burden of proof?" The World Bank Research Observer, Vol. 10, No. 1 (Feb.), pp. 1-19.

Alkire, S. and Foster, J. 2011."Counting and multidimensional poverty mapping." Journal of Public Economics. 95(7-8): 476-487.

Alkire, S., Meinzen-Dick, R., Peterman, A., Quisimbing, A., Seymour, G., and Vaz, A. 2012."The Women's Empowerment in Agriculture Index." IFPRI discussion paper 1240. Washington DC: International Food Policy Research Institute.

Alkire, S., Meinzen-Dick, R., Peterman, A., Quisimbing, A., Seymour, G., and Vaz, A. 2013. "The Women's Empowerment in Agriculture Index." World Development. 52:71-91.

Antonopoulos, R. (2009) 'The unpaid-paid work connection' ILO Working Paper 86 Geneva: ILO

Bhagowalia, P. Headey, D., and Kadiyala, S. 2012. "Agriculture, income and nutrition linkages in India: insights from a nationally representative survey." IFPRI Discussion Paper 01195. Washington DC: International Food Policy Research Institute.

Christian, P., 2014. The Distributional Consequences of Group Procurement: Evidence from a Randomized Trial of a Food Security Program in Rural India. Working Paper.

Chowdhury AMR, Bhuiya A. 2004. The wider impacts of BRAC poverty alleviation programme in Bangladesh. J IntDev; 16: 369-86.

Chowdhury, A. Mushtaque R., et al. 2013. "The Bangladesh paradox: exceptional health achievement despite economic poverty." The Lancet 382.9906: 17341745.

Coates, J., Frongillo, E., Rogers, B., Webb, P., Wilde, P., and Houser, R. 2006. "Commonalities in the experience of household food insecurity across cultures: what are measures missing?" The Journal of Nutrition. 136: 1438S-1448S.

Coffey, D., Gupta, A., Hathi, P., Spears, D., Srivastav, N. and Vyas, S., 2015. Culture and the health transition: Understanding sanitation behavior in rural north India. International Growth Centre. Working Paper, April. 
Cons, J. and Paprocki, K. 2010.“Contested credit landscapes: microcredit, selfhelp, and self-determination in rural Bangladesh." Third World Quarterly. 31(4): 637-654.

Dangour, A. D., Green, R., Hasler, B., Rushton, J., Shankar, B. and Waage, J. 2012. "Symposium 1: Food chain and health. Linking agriculture and lean in low- and middle-income countries: an interdisciplinary research agenda." Proceedings of the Nutrition Society.71: 222-228.

DeWalt, K. 1993. "Nutrition and the Commercialization of Agriculture: Ten years later.” Social Science \& Medicine.36(11): 1407 - 1416.

Drèze, J., \&Sen, A. 2013.An uncertain glory: India and its contradictions. Princeton University Press.

Elson, D. (1991) Male Bias in the Development Process Manchester: Manchester University Press

Eyben, R. and Napier-Moore, R. 2009.“Choosing Words with Care: Shifting meanings of women's empowerment in international development."Third World Quarterly. 30(2): 285-300.

FautschMacías, Y. and Glasauer, P. 2017. Guidelines for assessing nutritionrelatedKnowledge, Attitudes and Practices, Food and Agriculture Organisation, Rome. http://www.fao.org/docrep/019/i3545e/i3545e00.htm

FAO-IFAD-ILO, 2010.Gender dimensions of ruralemployment:differentiated pathways out of poverty. Rome: United Nations

FAO and FHI 360. 2016. Minimum Dietary Diversity for Women: A Guide for Measurement. Rome: FAO.

Fontana, M. 2011. 'Gender equality and WFP programmes: the significance of unpaid care work', Background paper for the World Food Programme: Rome

French Gates M. 2014."Putting women and girls at the center of development.Science.345(6202): 1273-1275

Gomez, M. Barrett, C. B., Raney, T., Pinstrup-Andersen, P., Meerman, J., Croppenstedt, A., Carisma, B., and Thompson, B. 2013.“Post-green revolution food systems and the triple burden of malnutrition" Food Policy. 42:129-138.

Gopalan C. 1996. Current food and nutrition situation in south Asian and southeast 
Asian countries. Biomed Environ Science 9:102-16

Haddad, L. 2013. "From Nutrition Plus to Nutrition Driven: How to realize the elusive potential of agriculture for nutrition?" Food and Nutrition Bulletin. 34(1): 39-44.

Harris-White, B. 2003. 'On understanding markets as social and political institutions in developing economies' in Chang Ha-Joon, ed. (2003) Rethinking Development Economics London: Anthem Press

Hausmann, Ricardo, DaniRodrik, and Andres Velasco. 2008. "Growth Diagnostics." Chap. 15 in The Washington Consensus Reconsidered: Towards a New Global Governance, ed. J. Stiglitz and N. Serra. New York: Oxford University Press.

Hausmann, R., Klinger, B. and Wagner, R., 2008 Doing Growth Diagnostics in Practice : A 'Mindbook', CID working Paper No.177, Centre for International Development, Harvard University, Boston.

Hawkes, C. Turner, R. and Waage, J. 2012. "Current and Planned Research on Agriculture for Improved Nutrition: A Mapping and a Gap Analysis. A report for DFID." http://r4d.dfid.gov.uk/Output/190847/ Accessed November 13, 2014.

Headey, Derek, et al. 2015. "The other Asian enigma: explaining the rapid reduction of undernutrition in Bangladesh." World Development 66: 749-761.

Hoddinott, J., 2012. Agriculture, health, and nutrition: toward conceptualizing the linkages. In: Fan, S., Pandya-Lorch, R. (Eds.), Reshaping Agriculture for Nutrition and Health. International Food Policy Research Institute, Washington, DC (Chapter 2).

Human resources for health in maternal, neonatal and reproductive health at community level: a profile of Bangladesh. Human Resources for Health Knowledge Hub.2011. http://www.hrhresourcecenter.org/node/3771

International Food Policy Research Institute (IFPRI). 2014. Global Nutrition Report 2014: Actions and Accountability to Accelerate the World's Progress on Nutrition. Washington, DC.

Israeli, 0., 2007.A Shapley-based decomposition of the R-square of a linear regression. The Journal of Economic Inequality, 5(2), pp.199-212.

Jain, M. and Zeller, M. 2015. "Do mothers not have the time to feed the children properly in Bangladesh?" International Food Policy Research Institute. January 15. Working Paper.

James, W.P. 1993. Food quality and human nutrition. Ciba Foundation Symposium, 175:80-92 
Jones, A., Ngure, F., Pelto, G., and Young, S. 2013. "What are we assessing when we measure food security? A compendium and review of current metrics."Advances in Nutrition.4: 481-505.

Kabeer, N. 2012."Women's economic empowerment and inclusive growth: labour markets and enterprise development." SOAS Discussion Paper. October. https://www.soas.ac.uk/cdpr/publications/papers/file80432.pdf

Kabeer, N. 1999. "Resources, agency, achievements: Reflections on the measurement of women's empowerment." Development and Change.30: 435464.

Kadiyala, S. Harris, J., Headey, D., Yosef, S., and Gillespie, S. 2014. "Agriculture and nutrition in India: mapping evidence to pathways." Annals of the New York Academy of Sciences.1-14.

Kennedy, E. 1994."Effects of sugarcane production in Southwestern Kenya on income and nutrition".In von Braun J and Kennedy, E. (eds.) Agricultural commercialisation, economicdevelopment and nutrition. Johns Hopkins University Press for the International Food Policy Research Institute: Baltimore, MD

Koehlmoos, TP, Islam, Z, Anwar, $\mathrm{S}$ et al. 2011. Health transcends poverty: the Bangladesh experience. in: D Balabanova, M McKee, A Mills (Eds.) Good health at low cost' 25 years on: what makes a successful health systems. London School of Hygiene and Tropical Medicine, London; 47-81

Lentz E. Under Review. "Complicating narratives of food and nutrition insecurity: domestic violence in rural Bangladesh."

Lentz, E., Narayanan, S., De, A. 2017. "Constraints to nutritional empowerment: Findings from multi-cite research in South Asia." Working Paper. Indira Gandhi Institute for Development Research.

Leroy, J., Ruel, M. and Olney, D. \. 2008. 'The micronutrient impact of multisectoral programs focusing on nutrition: examples of conditional cash transfers, microcredit and agricultural programs' Innocenti Review 5 at www.micronutrientforum.org/innocenti/

Malapit, H.J.L., and Quisumbing, A. R. 2014. What Dimensions of Women's Empowerment in Agriculture Matter for Nutrition-related Practices and Outcomes in Ghana? IFPRI Discussion Paper 01367.International Food Policy Research Institute http://www.ifpri.org/sites/default/files/publications/ifpridp01367.pdf

Meinzen-Dick, R. 2013. "How I learned to stop worrying and love the Index: Women's Empowerment in Agriculture.” International Food Policy Research Institute Reflections.April. 1-4. 
Meinzen-Dick, R., Behrman, J., Menon, P. and Quisumbing A. 2012. “Gender: a key dimension linking agricultural programs to improved nutrition and health." In: Fan, S., Pandya-Lorch, R. (Eds.), Reshaping Agriculture for Nutrition and Health. International Food Policy Research Institute, Washington, DC (Chapter 16).

Narayanan, S. and Gerber, N. 2017. Social safety nets for food and nutrition security in India, Global Food Security, http://dx.doi.org/10.1016/j.gfs.2017.05.001.

NNMB Technical Report No:24, National Nutrition Monitoring Bureau 2006 (Accessed at http://nnmbindia.org/NNMBReport06Nov20.pdf)

Paprocki, K. and Cons, J. 2014. "Life in a shrimp zone: aqua and other cultures of Bangladesh's coastal landscape." Journal of Peasant Studies. Online first: http://dx.doi.org/10.1080/03066150.2014.937709

Pinstrup-Andersen, P. 2014. "Chapter 2: Food Systems and Human Nutrition: Relationships and policy interventions." Eds. B. Thompson and L. Amoroso in Improving Diets and Nutrition: Food Based Approaches. Rome: Food and Agriculture Organization.

Pratley, P. 2016. “Associations between quantitative measures of women's empowerment and access to care and health status of mothers and their children: A systematic review of evidence from the developing world." Social Science and Medicine. 169: 119-131.

Ramalingaswami V, Jonsson U \& Rohde J (1997) Malnutrition: a South Asian enigma. In Malnutrition in South Asia: A Regional Profile. Rosa Publication no. 5, pp. 11-21.Kathmandu: UNICEF Regional Office for South Asia.

Rampal, Priya and Sudha Narayanan. 2017. "SCOWT in India” Work in Progress, Indira Gandhi Institute of Development Research, Mumbai

Robeyns, I. 2003. "Sen's capability approach and gender inequality: selecting relevant capabilities." Feminist Economics. 9(2-3): 61-92.

Rodrik, D., 2010. Diagnostics before Prescription. Journal of Economic Perspectives , 24 (3):33-44.www.jstor.org/stable/20799153.

Sen, A. 1999.Development as Freedom.New York: Knopf Double Day.

Smith, L., Kahn, F., Frankenberger, T., and Wadud, A. 2013. "Admissible evidence in the court of development evaluation?: The impact of CARE's Shouhardo project on child stunting in Bangladesh." World Development. 41:196-216. 
Spronk, I., Kullen, C., Burdon, C. and O'Connor, H., 2014. Relationship between nutrition knowledge and dietary intake.British Journal of Nutrition, 111(10), pp.1713-1726.

Sraboni, E., Quisumbing, A., Ahmed, A. 2013. “The Women's Empowerment in Agriculture Index: Results from the 2011-2012 Bangladesh Integrated Household Survey." April. International Food Policy Research Institute Report.http://www.ifpri.org/sites/default/files/publications/weaitr.pdf

UN Women. 2015. Progress of the World's Women 2015-2016: Transforming economies, realizing rights. New York: United Nations

UN Women. 2014. World Survey on the Role of Women in Development; Gender Equality and Sustainable Development. New York: United Nations.

Vaz, A., P. Pratley \&S.Alkire (2016) Measuring Women's Autonomy in Chad Using the Relative Autonomy Index, Feminist Economics, 22:1, 264-294, DOI: 10.1080/13545701.2015.1108991

Victora, C. Adair, L., Fall, C., Hallal, P., Martorell, R., Richter, L., and Sachdev Singh, H. et al. 2008. "Maternal and child undernutrition: consequences for adult health and human capital." The Lancet.371: 340-357. 
Table 1: The WENI Grid

\begin{tabular}{|c|c|c|c|c|c|c|}
\hline & & \multicolumn{5}{|c|}{ DIMENSIONS } \\
\hline & & $\begin{array}{l}\text { Knowledge } \\
\text { (To have knowledge of...) }\end{array}$ & $\begin{array}{l}\text { Resources } \\
\text { (material and social resources, structural conditions /norms) }\end{array}$ & $\begin{array}{l}\text { Agency } \\
\text { (Executive \& Implementation) }\end{array}$ & $\begin{array}{l}\text { Intermediate } \\
\text { Achievements }\end{array}$ & $\begin{array}{l}\text { Final } \\
\text { Outcomes }\end{array}$ \\
\hline 1 & 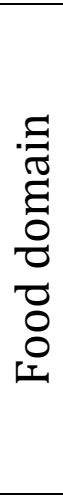 & $\begin{array}{l}\text { Knowledge of } \\
\text { 1. Nutrition } \\
\text { 2. Special diets } \\
\text { 3. Government schemes } \\
\text { (for self-employed, } \\
\text { trainings, farming) }\end{array}$ & $\begin{array}{l}\text { 1. Access to paid work with adequate remuneration } \\
\text { 2.Opportunities for work throughout the year } \\
\text { (Private/government/ NGOs) } \\
\text { 3. Opportunities of self-employment (capital/credit, market, } \\
\text { livestock, land, forest access, training) } \\
\text { 4. Access to food (Market purchases Production, State schemes } \\
\text { CPR NGOs/Civil society Org/SHGs) } \\
\text { 5. Norms around consumption } \\
\text { (a) Eating order } \\
\text { (b) Fasting } \\
\text { (c) Taboos (vegetarianism, milk avoidance) } \\
\text { 6. Time available (to do paid work, or collect and prepare food) }\end{array}$ & $\begin{array}{l}\text { 1. Decisions around } \\
\text { (a) Food production } \\
\text { (b) Procurement } \\
\text { (c) Preparation } \\
\text { (d) Distribution } \\
\text { 2. Control over income and } \\
\text { expenditure on food } \\
\text { budgets and types of food }\end{array}$ & 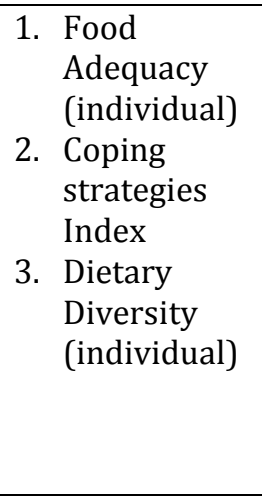 & $\begin{array}{c}\text { BMI } \\
\text { MUAC } \\
\text { Anaemia }\end{array}$ \\
\hline 2 & 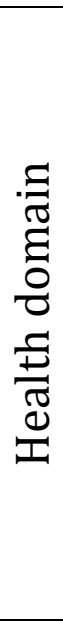 & $\begin{array}{l}\text { Knowledge of } \\
\text { 1. WASH } \\
\text { 2. Immunization } \\
\text { 3. Any specific endemic } \\
\text { disease }\end{array}$ & $\begin{array}{l}\text { 1. Working conditions } \\
\text { (a) Work effort and intensity (in both paid and } \\
\text { unpaid work) } \\
\text { (b) Exposure to hazardous conditions, chemicals, } \\
\text { environment } \\
\text { (c) Fair distribution between paid \& unpaid work } \\
\text { Technologies and infrastructure (type, time, effort) } \\
\text { (a) Fuel } \\
\text { (b) Water } \\
\text { (c) At work: on and off-farm } \\
\text { F. } \\
\text { Facilities (Gov and private, traditional, temple, etc.) } \\
\text { and assistance in tasks from others (household, paid, } \\
\text { community, etc.) } \\
4 . \quad \text { Financing (subsidies) } \\
5 . \quad \text { Initiatives for specific diseases (polio, malaria) }\end{array}$ & $\begin{array}{l}\text { 1. Decisions around } \\
\text { (a) Health seeking } \\
\text { (b) Toilet construction } \\
\text { (c) WASH } \\
\text { 2. Control over time } \\
\text { (a) Leisure } \\
\text { (b) Type of work } \\
\text { (c) Tasks, sleep/rest } \\
\text { 3. Control over use of } \\
\text { money for health } \\
\text { relative investments }\end{array}$ & $\begin{array}{l}\text { Morbidity } \\
\text { 1. Chronic } \\
\text { 2. Long-term } \\
\text { 3. Temporary } \\
\text { 4. Specific } \\
\text { diseases } \\
\text { mental, } \\
\text { menopausal }\end{array}$ & \\
\hline
\end{tabular}




\begin{tabular}{|c|c|c|c|c|c|}
\hline 3 & 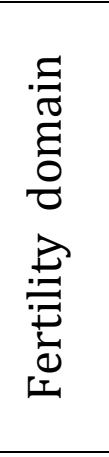 & $\begin{array}{l}\text { 1. Contraception. } \\
\text { 2. Maternal health } \\
\text { during Pregnancy } \\
\text { and lactation } \\
\text { /feeding practices } \\
\text { 3. Government } \\
\text { schemes (for } \\
\text { antenatal and } \\
\text { postnatal care, } \\
\text { maternity } \\
\text { entitlements) } \\
\end{array}$ & $\begin{array}{ll}\text { 1. } & \text { Facilities } \\
\text { 2. } & \text { Financing } \\
\text { 3. Schemes } \\
\text { 4. } & \text { Contraception }\end{array}$ & $\begin{array}{l}\text { Decisions around } \\
\text { (a) Marriage } \\
\text { (b) Children } \\
\text { (c) Contraception } \\
\text { (d) Food during } \\
\text { pregnancy and lactation }\end{array}$ & $\begin{array}{l}\text { 1. Age at } \\
\text { marriage } \\
\text { 2. Age at first } \\
\text { pregnancy } \\
\text { 3. Birth spacing } \\
\text { 4. Parity } \\
\text { 5. Child } \\
\text { mortality }\end{array}$ \\
\hline 3 & $\begin{array}{l}\text { INSTI } \\
\text { TUTI } \\
\text { ONS }\end{array}$ & $\begin{array}{ll}\text { 1. } & \text { Decisions around } \\
\text { 2. } & \text { Access to media (n } \\
\text { 3. } & \text { Expression of diss } \\
\text { 4. } & \text { Sources of conflict } \\
\text { 5. } & \text { Government progr }\end{array}$ & $\begin{array}{l}\text { ovement, Freedom to visit } \\
\text { wspaper, radio, TV), Bank a } \\
\text { isfaction on disagreement } \\
\text { ms }\end{array}$ & $\begin{array}{l}\text { port at the time of crisis } \\
\text { e access and use, as informa }\end{array}$ & n source; voting \\
\hline
\end{tabular}


Table 2: Shapley-Owen decompositions by WENI domain-dimensions for selected states in India (2005-06)

Note: Shapley-Owen results are subject to caveats with respect to data coverage, exiting variation in the sample, etc. which are analysed in a forthcoming paper.

\begin{tabular}{|c|c|c|c|c|c|c|c|c|c|c|c|c|c|c|}
\hline \multirow{2}{*}{ S.No } & \multirow{2}{*}{$\begin{array}{c}\text { Domain- } \\
\text { Dimension }\end{array}$} & \multirow{2}{*}{$\begin{array}{c}\text { Number } \\
\text { of } \\
\text { questions } \\
\text { in NFHS } \\
\text { GRID }\end{array}$} & \multicolumn{2}{|c|}{ Uttar Pradesh } & \multicolumn{2}{|c|}{ Tamil Nadu } & \multicolumn{2}{|c|}{ Kerala } & \multicolumn{2}{|c|}{ Bihar } & \multicolumn{2}{|c|}{ Odisha } & \multicolumn{2}{|c|}{ Chhattisgarh } \\
\hline & & & $\begin{array}{l}\text { Shapley } \\
\text { value }\end{array}$ & Percent & $\begin{array}{l}\text { Shapley } \\
\text { value }\end{array}$ & Percent & $\begin{array}{l}\text { Shapley } \\
\text { value }\end{array}$ & Percent & $\begin{array}{l}\text { Shapley } \\
\text { value }\end{array}$ & Percent & $\begin{array}{l}\text { Shapley } \\
\text { value }\end{array}$ & Percent & $\begin{array}{c}\text { Shapley } \\
\text { value }\end{array}$ & Percent \\
\hline & R-squared & & \multicolumn{2}{|c|}{$R^{2}=22.41$} & \multicolumn{2}{|c|}{$\mathbf{R}^{2}=33.091$} & \multicolumn{2}{|c|}{$\mathbf{R}^{2}=37.778$} & \multicolumn{2}{|c|}{$\mathbf{R}^{2}=32.3$} & \multicolumn{2}{|c|}{$\mathbf{R}^{2}=27.817$} & \multicolumn{2}{|c|}{$R^{2}=23.861$} \\
\hline 1 & Food Knowledge & NA & NA & NA & NA & NA & NA & NA & NA & NA & NA & NA & NA & NA \\
\hline 2 & Food Resource & 9 & 0.008 & $4 \%$ & 0.016 & $5 \%$ & 0.015 & $4 \%$ & 0.032 & $10 \%$ & 0.012 & $4 \%$ & 0.012 & $5 \%$ \\
\hline 3 & Food Agency & 5 & 0.008 & $4 \%$ & 0.015 & $5 \%$ & 0.022 & $6 \%$ & 0.010 & $3 \%$ & 0.010 & $4 \%$ & 0.007 & $3 \%$ \\
\hline 4 & Health Knowledge & 8 & 0.013 & $6 \%$ & 0.024 & $7 \%$ & 0.019 & $5 \%$ & 0.019 & $6 \%$ & 0.026 & $9 \%$ & 0.012 & $5 \%$ \\
\hline 5 & Health Resource & 28 & 0.032 & $14 \%$ & 0.056 & $17 \%$ & 0.051 & $14 \%$ & 0.052 & $16 \%$ & 0.061 & $22 \%$ & 0.046 & $19 \%$ \\
\hline 6 & Health Agency & 4 & 0.005 & $2 \%$ & 0.007 & $2 \%$ & 0.017 & $4 \%$ & 0.004 & $1 \%$ & 0.004 & $1 \%$ & 0.002 & $1 \%$ \\
\hline 7 & $\begin{array}{l}\text { Fertility } \\
\text { Knowledge }\end{array}$ & 1 & 0.002 & $1 \%$ & 0.007 & $2 \%$ & 0.004 & $1 \%$ & 0.003 & $1 \%$ & 0.002 & $1 \%$ & 0.001 & $0 \%$ \\
\hline 8 & Fertility Resource & 24 & 0.017 & $8 \%$ & 0.028 & $8 \%$ & 0.045 & $12 \%$ & 0.039 & $12 \%$ & 0.021 & $8 \%$ & 0.029 & $12 \%$ \\
\hline 9 & Fertility Agency & 5 & 0.008 & $3 \%$ & 0.010 & $3 \%$ & 0.014 & $4 \%$ & 0.009 & $3 \%$ & 0.006 & $2 \%$ & 0.007 & $3 \%$ \\
\hline 10 & Institutions & 14 & 0.033 & $15 \%$ & 0.046 & $14 \%$ & 0.053 & $14 \%$ & 0.052 & $16 \%$ & 0.047 & $17 \%$ & 0.041 & $17 \%$ \\
\hline 11 & Other controls & 13 & 0.063 & $28 \%$ & 0.074 & $22 \%$ & 0.091 & $24 \%$ & 0.055 & $17 \%$ & 0.049 & $17 \%$ & 0.055 & $23 \%$ \\
\hline Total & & 111 & 0.191 & $85 \%$ & 0.283 & $86 \%$ & 0.330 & $87 \%$ & 0.275 & $86 \%$ & 0.238 & $85 \%$ & 0.212 & $89 \%$ \\
\hline
\end{tabular}


Table 3: Shapley values by Resources, Agency, Knowledge

\begin{tabular}{lrrr}
\hline State & Resources & \multicolumn{1}{c}{ Agency } & Knowledge \\
\hline Uttar Pradesh & 0.058 & 0.015 & 0.021 \\
Tamil Nadu & 0.099 & 0.032 & 0.032 \\
Kerala & 0.111 & 0.022 & 0.053 \\
Bihar & 0.123 & 0.022 & 0.024 \\
Odisha & 0.094 & 0.028 & 0.020 \\
Chhattisgarh & 0.087 & 0.013 & 0.016 \\
\hline
\end{tabular}

Table 4: Shapley values decomposed by domains.

\begin{tabular}{lccccc}
\hline & Food & Health & Fertility & Institutions & $\begin{array}{c}\text { Shapley } \\
\text { Values }\end{array}$ \\
\hline Uttar Pradesh & 0.017 & 0.051 & 0.027 & 0.033 & $\mathbf{0 . 1 2 7}$ \\
Tamil Nadu & 0.031 & 0.087 & 0.045 & 0.046 & $\mathbf{0 . 2 0 9}$ \\
Kerala & 0.037 & 0.087 & 0.063 & 0.053 & $\mathbf{0 . 2 3 9}$ \\
Bihar & 0.042 & 0.075 & 0.051 & 0.052 & $\mathbf{0 . 2 2 0}$ \\
Odisha & 0.023 & 0.090 & 0.029 & 0.047 & $\mathbf{0 . 1 8 9}$ \\
Chhattisgarh & 0.019 & 0.060 & 0.037 & 0.041 & $\mathbf{0 . 1 5 7}$ \\
\hline
\end{tabular}

Shapley-Owen results are subject to caveats with respect to data coverage, exiting variation in the sample, etc. which are analysed in a forthcoming paper. 
